\title{
Dossier: Fundamentos físicos y metafísicos del pensamiento político medieval. Antecedentes antiguos y proyecciones modernas. Parte I Presentación
}

\author{
( Jazmín Ferreiro \\ Universidad de Buenos Aires-Universidad Nacional de General Sarmiento, \\ Argentina
}

El presente dossier recupera algunos de los aportes expuestos en las II Jornadas de Filosofía Antigua y Medieval "Los fundamentos físicos y metafísicos de lo político en la Edad Media. Antecedentes antiguos y proyecciones en la Modernidad Temprana", desarrolladas a fines del año 2019 en la Universidad Nacional de General Sarmiento, y realizadas en el marco de los proyectos de investigación "Derivas de la noción de monarquía. Los antecedentes tardo-antiguos y la proyección moderna de una categoría teológico-política medieval" (UBACyT 20020170200387BA de la programación científica 2018-2020) y "La irrupción del concepto de natura en el discurso político y científico del medioevo tardío y temprana modernidad" (Proyecto del Instituto de Ciencias de la UNGS).

Como el título anticipa, es posible reconocer fundamentos de diversa índole en los tratados políticos medievales. En el arco que se extiende entre textos como De civitate Dei, de Agustín de Hipona y De concordantia Catholica de Nicolás de Cusa, identificamos dos tipos de fundamentos que sustentan las reflexiones acerca de la vida política, uno, metafísico, que con cierta constancia se expresa a través de un vocabulario de raigambre neoplatónica, y otro de tipo más empírico, que se nutre de un vocabulario aristotélico pero que se extiende a otras fuentes. A partir de las tesis propuestas por Walter Ullmann (1961) sobre la presencia de estos dos tipos de fundamentos, y siguiendo la línea de la interpretación medieval del pensamiento de Aristóteles, en particular, sobre la operatividad de la noción de naturaleza en la producción de textos políticos, Bertelloni $(2005 ; 2011)$ ha descripto este fenómeno de recepción de las obras aristotélicas (en particular de los libri morales de Aristóteles) y de su incorporación al pensamiento político como un pasaje desde una fundamentación teológica de la política hacia otra de carácter teórico-filosófica que se da a partir del siglo XIII en el occidente latino.

La recepción de textos científico-naturalistas de la antigüedad clásica modifica la posición de pensadores como Tomás de Aquino, quien a partir de la recepción de la obra de Aristóteles se esfuerza en desarrollar una comprensión de las causas que investigan las ciencias particulares y así comprender "las causas próximas de nuestro mundo de la experiencia" (Castello Dubra 2006: 85). El predominio de una nueva perspectiva que asocia la búsqueda de la verdad a su comprobación mediante la experiencia tiene un alcance teórico pero también metodológico. Se registra una transformación en los métodos de investigación, a la vez que un uso frecuente de metáforas que invierten el lugar 
de la prueba y una recurrente apelación a la naturaleza, que adquiere a partir del último cuarto del siglo XIII un fuerte carácter empírico, devaluando el carácter especulativo tan común en períodos anteriores. En efecto, la naturaleza comienza a ser concebida como una realidad que puede ser objeto de conocimiento basándose en la observación racional, y en la deducción de experiencias empíricas (Black 2003; Coleman 2000). Así, tanto la recepción de textos griegos en el mundo latino como el fundamental influjo de la metodología de investigación escolástica desarrollada en las florecientes universidades medievales explican el novedoso tratamiento que recibe el concepto de naturaleza. Sin embargo, hay que destacar que esta incorporación teórica no supuso un reemplazo de otras fuentes sino más bien una asimilación no siempre fácil.

Resulta así imprescindible tener en cuenta la articulación entre tradiciones diversas. Un autor cuyas obras representan cabalmente esta confluencia de doctrinas es Alberto Magno. Una vez traducido el Liber de causis en el siglo XII y comentado por el Doctor de Colonia en la segunda mitad del XIII, se inaugura una tradición que intenta pensar la causalidad metafísica a partir del planteo del problema de la transmisión de la potencia desde una causa primera -que se identifica con Dios- hacia las causas segundas. Esta problemática neoplatónica fue abordada por el discípulo dilecto de Alberto Magno, Tomás de Aquino, en su obra De regno. Es sabido que a la hora de fundamentar la necesidad de la comunidad política y del gobierno Aquino apela al naturalismo político de Aristóteles, de gran impacto en la teoría política medieval (Ferreiro, 2020). Sin embargo, cuando se trata de ofrecer un fundamento de la necesidad de que el gobierno sea monárquico, Tomás introduce una serie de axiomas que se referencian en otra tradición neoplatónica. Al afirmar la preeminencia de la unidad sobre la multiplicidad se apoya en citas de los Elementos de teología de Proclo (toda pluralidad se deriva de la unidad) (De regno I, 2.), y al sostener que cuanto más unida es una fuerza más efectiva es, se apoya en el anónimo Liber de causis.

En el tratado De Monarchia de Dante Alighieri, escrito a principios del siglo XIV, también se verifica la influencia doctrinal ejercida tanto por Alberto Magno como por Tomás de Aquino (son clásicos los estudios de Francesco Ercole de 1921, Bruno Nardi 1967 y E. Gilson 1939). En efecto, muchos de los conceptos provenientes de la filosofía aristotélica y neoplatónica que el gran poeta italiano utilizó al escribir su obra política resultan del pensamiento de los maestros dominicos. En el texto de Dante aparece, nuevamente, el uso de la noción de Monarquía según su origen teológico aunque aplicada específicamente al ámbito político temporal (Bertelloni, 1981). La concepción expuesta por Dante deviene de la utilización de la noción de causalidad final conectada con el concepto de ordinatio que implica una relación entre la parte y el todo correspondiente con un tipo de causalidad paradigmática (Arroche, 2010). En la construcción metafísica de la noción de Monarquía que lleva a cabo Dante también resulta fundamental el concepto de potencia tal como es concebido por la tradición filosófica neoplatónica (Arroche, 2017; 2015).

Los representantes cabales de la tradición filosófica inaugurada por Alberto Magno son sus discípulos y continuadores germanos como, por ejemplo, Ulrico de Estrasburgo, Teodorico de Freiberg, Eckhart y Bertoldo de Moosburg. En el caso de todos estos pensadores observamos un nuevo giro de la relación entre metafísica y política. En sus interpretaciones sobre el Liber de causis, Alberto Magno y Eckhart utilizan metáforas políticas y castrenses que intentan ilustrar la relación entre las causas segundas y la primera. Una situación similar se da en la Expositio Procli de Bertoldo de Moosburg. Este autor considera la existencia de un princeps universalis y de varios principes partiales subordinados. Ahora bien, en la Expositio de Bertoldo no sólo hallamos la recurrencia a una metáfora política para explicar una cuestión metafísica, sino que conceptualiza la relación entre esa instancia primera y las instancias segundas en el orden político a propósito de un análisis de los conceptos de regnum y monarchia. 
En ese sentido, trata de demostrar cómo esta relación política es un reflejo de una relación metafísica que se da tanto en el ámbito de lo corpóreo (lo natural o civil, in naturalibus sive in civilibus), como de lo anímico y de lo sobrenatural (Ludueña, 2014; 2015; 2017). En Nicolás de Cusa, el vocabulario forjado en una tradición fuertemente especulativa se articula con el discurso científico de un modo muy particular (Strunk, 2019; Hoenen, 1995). Podemos tomar el concepto de ecclesia como ejemplo. Dicho concepto es central para la conformación de una comprensión de lo político que remita más allá de la unión como simple acuerdo de voluntades. En De concordantia catholica Nicolás de Cusa presenta su concepto de ecclesia como una realidad espiritual omniabarcante. El reino del espíritu se despliega en una serie escalonada de niveles que se corresponden o guardan armonía con la totalidad de lo que es. La totalidad de lo que es incluye lo mineral, vegetal, animal y espiritual. Para mostrar la armonía y al mismo tiempo la diferencia de lo espiritual respecto de las otras instancias el Cusano recurre constantemente al discurso científico que circulaba en su época. Las fuentes explícitas remiten a la esfera de Sacrobosco, al conocimiento astronómico que en su más alto grado de desarrollo concuerda con el saber revelado more theologico (cf. De Concordantia Catholica hXIV1, nn.11-12). Nicolás de Cusa establece un paralelismo entre las instituciones del poder temporal y las del poder espiritual. Pero son otras las estrategias que utiliza para solucionar los problemas específicos que se encuentran en cada una de estas esferas en las que se divide la cristiandad (D'Ascenzo, 2019).

Dentro de este amplio arco interpretativo que procura explorar los fundamentos físicos y metafísicos de la teoría política medieval, y sus confluencias armónicas o problemáticas, se inscriben los aportes particulares de los artículos que aquí presentamos. En el primero de ellos, Ezequiel Ludueña, quien, en varias investigaciones indagó las vías por las cuales las distintas corrientes neoplatónicas paganas pasaron de la Edad Media a la temprana Modernidad, explora la tradición neoplatónica tal como es asimilada por el destacado albertista del siglo XIV. En efecto, en "Proclo, Dionisio y el pensamiento eriugeniano en la Expositio de Bertoldo de Moosburg" Ludueña busca mostrar cómo, en torno a la posible articulación entre el orden de la providencia voluntaria y el orden de la providencia natural, se da una encuentro entre el platonismo pagano y el platonismo cristiano gracias al rol mediador de Escoto Eriúgena.

Andrea Paul también explora la posible concordia entre paganismo y cristianismo a través del impacto de fuentes herméticas en un autor renacentista. Tal es la tesis que despliega en su artículo "Docta religio y pia philosophia en el pensamiento de Marsilio Ficino: Las fuentes herméticas y la búsqueda de una concordia".

El encuentro de las dos tradiciones a las que hicimos referencia es analizado por Victoria Arroche, quien muestra que en el caso de la Monarchia de Dante Alighieri es posible notar la convivencia de elementos neoplatónicos con elementos que provienen de una corriente de pensamiento que se forma a partir de la recepción tardía de la obra aristotélica. En "Dos tesis historiográficas de la primera mitad del siglo XX en torno al uso de los conceptos de naturaleza y finalidad en el pensamiento político de Dante Alighieri", Arroche presenta en detalle dos posturas historiográficas en tensión, las de Ercole y Nardi, poniendo en evidencia la compleja síntesis presente en la obra política de Dante entre tradiciones dispares como la agustiniana y la aristotélico-tomista.

Finalmente, en su artículo "La importancia de rastrear el pensamiento de Aristóteles en la Nueva España", Virginia Aspe Armella hace un aporte muy relevante en función del reconocimiento del influjo aristotélico en tierras americanas. Enunciando la importancia de pensar a partir de la lengua y de la geografía, Aspe Armella repone los antecedentes de la formación de los frailes que llegan a América en el siglo XVI y el protagonismo aristotélico especialmente en el periodo novohispano en México. 


\section{Dibliografía}

" Arroche, V. (2010). Ordinatio y Reductio: dos conceptos operativos en la argumentación política dantesca. Pedro Roche Arnas (Coord.) El pensamiento político en la Edad Media. España: Ed. Fundación Ramón Areces.

" Arroche, V. (2015). La presencia del Liber de causis en la doctrina dantesca de la potencia humana. Mediaevalia Americana 1/2.

»Arroche, V. (2017). The Liber de causis and the formula potentia sive virtus in Dante's political philosophy. Les Éléments de théologie et le Livre des causes du $V^{\circ}$ au XVII siècle, Brill.

»Bertelloni, F. (2005). Algunas reinterpretaciones de la causalidad final aristotélica en la teoría política medieval, Cadernos de História e Filosofia da Ciênca, 15/2.

» Bertelloni, F. (1981). Filosofía política y teología de la Historia en la teoría dantesca del Imperio. Patristica Et Mediævalia, 2, 37-66.

» Bertelloni, F. (2011). Natura multipliciter dicitur. Scripta mediaevalia. Vol.2. n².

» Black, A. (2003). Church, State and Community: Historical and Comparative Perspectives. United Kingdom: Ashgate Variorum.

" Castello Dubra, J. (2006). Tomás de Aquino y las condiciones de posibilidad de una ciencia natural: la eficiencia de las causas segundas. Patrística et Mediaevalia, XXVII.

" Coleman, J. (2000). A History of Political Thought, From the Middle Ages to the Renaissance. USA: Blackwell.

" D’Ascenzo, M. (2019) Renovatio imperii et salus populi en Nicolás de Cusa. Publicaciones de Eventos Académicos de la Facultad de Filosofía y Letras de la Universidad de Buenos Aires, disponible en: www.eventosacademicos.filo.uba.ar/index. php/JIBEMMT/JIBEMMT-2017

»Ercole, F. (1921). Medio Evo e Rinascimento nella dottina política di Dante. Giornale Dantesco, XXIV.

» Ferreiro, J. (2011). Acerca de la existencia de vínculos de dominio in statu innocentiae. La propuesta tomista frente a la formulación agustiniana. Scripta Mediaevalia, vol. $4, n^{\circ} 2$.

»Ferreiro, J. (2020). El naturalismo político aristotélico en el pensamiento político medieval. Continuidades y rupturas. En Aspe, V., Corso, L. Ross, A. (comps.) Lecturas medievales y renacentistas de Aristóteles. Colección Filosófica. Mexico: Universidad Panamericana México.

" Gilson, E. (1939). La philosophie dans la "Monarchie". Dante et la Philosophie. Paris: Librairie Philosophique J. Vrin.

"Hoenen (1995). Ista prius inaudita, Medioevo, 21.

" Ludueña, E. (2014). Eriúgena en el siglo XIV: Su presencia en la Expositio de Bertoldo de Moosburg. Scintilla: Revista de Filosofía e Mistica Medieval, 10/2.

"Ludueña, E. (2015). Creatio y determinatio en la Escuela Renana. Princípios, n. 22/37, Departamento de Filosofía de la Universidade do Rio Grande do Norte.

"Ludueña, E. (2017). Dioses, inteligencias y ángeles de Alberto Magno a Bertoldo 
de Moosburg. Cuadernos de filosofía,66.

"Nardi, B. (1967). Saggi di Filosofia Dantesca, Firenze: Ed. La Nuova Italia.

"Strunk, N. (2019). Motion, Space and Early Modern Re-formations of the Cosmos. En Burton, S, Hollmann, J., Parker, E. (eds.), Nicholas of Cusa and the making of the early modern world. Boston: Brill.

"Ullmann, W. (1961). Principles of Government and Politics in the Middle Ages. New York: Barnes and Noble. 
